\title{
UTILIZAÇÃO DE RESÍDUOS SÓLIDOS DA INDÚSTRIA PAPELEIRA COMO MATÉRIA-PRIMA PARA FABRICAÇÃO DE TIJOLOS
}

Leandro Lopes Izidio'

Gimerson Weigert Subtil ${ }^{2}$

Alexandre Augusto de Andrade ${ }^{3}$

RESUMO: Os Resíduos Dregs e a Lama de Cal são gerados nas indústrias papeleiras que utilizam o ciclo de recuperação química em seu processo de fabricação, esses resíduos são destinados, geralmente, em aterros industriais provocando um custo econômico e ambiental para o gerador. Os estudos realizados para minimizar esses impactos envolvem a utilização desses resíduos como parte da matéria prima para fabricação de tijolos. Para o processo de fabricação dos tijolos serão feitas misturas entre os resíduos e a argila, onde passaram pelos testes de perda ao fogo, retração linear, tensão de ruptura, absorção de água e densidade aparente que revelaram a qualidade desses tijolos, mostrando se os mesmos obedecem aos padrões estabelecidos pela ABNT. A partir dos resultados, foi feita comparação entre as porcentagens das misturas e a argila em si, comprovando que é possível a utilização desses resíduos para a fabricação de tijolos.

\footnotetext{
${ }^{1}$ Acadêmico do curso de Engenharia Química da Faculdade de Telêmaco Borba - FATEB, Telêmaco Borba - Paraná. leandoflopinho@hotmail.com

${ }^{2}$ Acadêmico do curso de Engenharia Química da Faculdade de Telêmaco Borba - FATEB, Telêmaco Borba - Paraná. Weigert subtil@hotmail.com

${ }^{3}$ Orientador, Professor mestre do Curso de Engenharia Química da Faculdade de Telêmaco Borba FATEB. aandrade@klabin.com.br
} 
Palavras- chave: Dregs. Lama de Cal. Recuperação Química.

\subsection{INTRODUÇÃo}

O meio-ambiente sofreu e vem sofrendo alterações significativas ao decorrer dos anos, mas aos poucos isso vem mudando vagarosamente devido a atitudes ambientalmente corretas e a grandes campanhas de conscientização ambientais iniciadas por instituições públicas, privadas e filantrópicas.

A geração de resíduos vem desencadeando preocupação na ordem humana, pois quase todos os setores da economia mundial despejam diariamente toneladas de rejeito ao ambiente, contudo as fábricas de papel e celulose deparam-se com problemas de ordem ambiental devido à grande quantidade de resíduos gerados. Isso tem levado vários países, dentre eles o Brasil, a tornarem suas legislações cada vez mais restritivas no sentido de, por exemplo, estabelecer limites de emissões e de obrigar os geradores a tratar e destinar adequadamente seus resíduos. A opção por aterro sanitário para disposição final destes resíduos passa a ser inviável em função dos altos custos para implantação e manutenção, além da exigência de cuidados especiais no manuseio tendo em vista os riscos de contaminação ambiental.

No caso específico dos resíduos sólidos industriais, várias são as tecnologias empregadas para tratamento e destinação adequada, dentre as quais destaca-se o coprocessamento que é definido pela Deliberação Normativa - DN n 83 de 2005 da Comissão de Política Ambiental de Minas Gerais - COPAM como sendo utilização de resíduos sólidos industriais para recuperação e/ou economia de energia e/ou substituição de matérias-primas.

$\mathrm{Na}$ indústria cimenteira, o co-processamento de resíduos é regido pela Resolução $n^{\circ} 264$ de 1999 do Conselho Nacional do Meio Ambiente - CONAMA que dispõe sobre o licenciamento de fornos rotativos de produção de clínquer para utilização dessa técnica. Segundo essa resolução, os resíduos podem ser utilizados como substitutos da matériaprima desde que apresentem características similares às dos componentes normalmente 
empregados na produção de clínquer, incluindo os materiais mineralizadores e fundentes. É excluído o co-processamento de resíduos domiciliares brutos, dos resíduos de serviços de saúde, dos radioativos, explosivos, organoclorados, agrotóxicos e afins, ressaltando que a quantidade de resíduo gerado ou estocado deve ser suficiente para justificar sua utilização como substituto parcial de matéria-prima e/ou de combustível, no sistema forno de produção de clínquer, após a realização e aprovação de teste de queima. Essa resolução ressalta que o co-processamento de resíduos em fornos de produção de clínquer deve ser feito de modo a garantir a manutenção da qualidade ambiental, evitar danos e riscos à saúde e atender aos padrões de emissão fixados. Ressalta também que o produto final, no caso o cimento, resultante do co-processamento em fornos de clínquer não deve agregar substâncias ou elementos em quantidades tais que possam afetar a saúde humana e o meio ambiente.

Para a indústria de cerâmica vermelhas, embora não exista legislação específica para o co-processamento de resíduos, cuidados e precauções semelhantes devem ser priorizadas para garantir satisfatórias qualidades técnico-ambientais dos materiais cerâmicos produzidos.

O co-processamento dos resíduos sólidos industriais não é uma prática recente e tem se mostrado viável em vários países de primeiro mundo. As principais razões que tem influenciado a utilização dessa técnica são o esgotamento das reservas de matériasprimas e o crescente volume de resíduos sólidos gerados que põem em risco a saúde pública, ocupam o espaço em aterros e degradam os recursos naturais, além de gerar altos custos para a sociedade como um todo (MENEZES et al. 2002).

A indústria cerâmica se destaca nesse contexto pelo seu potencial em coprocessar resíduos em virtude de possuir elevado volume de produção, e também pelo fato de alguns resíduos, aliados às características físico-químicas da matéria-prima (argila) e às particularidades do processo produtivo, poderem possibilitar vantagens à indústria e ao processo, tais como, economia e diversificação da oferta de matérias primas, redução do consumo de energia e, por conseguinte, redução de custos (ALVES; BALDO, 1998).

De acordo com as características e influências sobre as propriedades das massas e materiais cerâmicos, os resíduos sólidos industriais podem ser agrupados em redutores 
de plasticidade, fundentes e combustíveis, ressaltando-se que uma classificação sistemática é muito complexa, em virtude da possível variabilidade dos efeitos causados nessas propriedades em função da porcentagem de resíduo co-processado, temperatura e patamar de queima, por exemplo.

O co-processamento de resíduos oriundos de diferentes processos industriais pela indústria cerâmica, tem sido objeto de estudo por diversos pesquisadores que buscam soluções que conciliem os aspectos técnicos e ambientais. Dentre os citados na literatura, destacam-se os da mineração, da indústria de celulose e papel, metalurgia, siderurgia, galvanoplastia e lodos de estações de tratamento de água e de efluentes dentre outros. Sendo assim, o co-processamento de determinados resíduos sólidos industriais em argila para produção de materiais cerâmicos pode ser vantajoso tanto para a indústria geradora quanto para indústria absorvedora. Para esta, cita-se vantagens como o prolongamento da vida útil das jazidas de matéria-prima, possibilidade de redução do consumo de energia e obtenção de melhorias na qualidade final dos materiais cerâmicos. Para os geradores, a minimização de passivos ambientais e de riscos de contaminação do ambiente pelo resíduo, diminuição de custos no tratamento e disposição final do resíduo. Isso contribuirá diretamente para minimização de impactos ambientais negativos que refletirá indiretamente na melhoria da qualidade de vida humana.

As pesquisas na área ambiental tornam-se uma arma importante para a minimização desses problemas por garantirem um novo rumo na disposição dos resíduos e uma maneira inovadora de utilizá-los. Sendo o objetivo do presente trabalho a utilização dos resíduos sólidos da indústria de Celulose e papel para a fabricação de tijolos, visando diminuir a quantidade de resíduos descartados em aterros.

\section{DESENVOLVIMENTO}

Foram utilizados para este trabalho lama de cal e dregs provenientes da indústria de celulose e papel e a argila foi retirada dos barreiros do município de Sapopema - PR. Os materiais foram caracterizados em suas propriedades tanto separadamente como em misturas (argila + resíduos), sendo que as amostras preparadas foram analisadas tanto após queima em temperaturas de referência industrial. 
Os testes foram realizadas primeiramente para $A$ (argila pura), em seguida B (argila $+5 \%$ de dregs), C (argila $+10 \%$ de dregs), D (argila $+5 \%$ lama de cal) e por fim $E$ (argila + 10\% lama de cal). Os corpos de prova com dimensão de $100 \times 20 \times 15$ mm foram secos em estufa a $110^{\circ} \mathrm{C}$ e queimados a temperatura de $850^{\circ} \mathrm{C}$ e $950^{\circ} \mathrm{C}$ então foram realizados os testes descritos a seguir para a temperatura de $850^{\circ} \mathrm{C}$.

As propriedades cerâmicas obtidas foram: absorção de água, massa especifica aparente (ou densidade aparente), resistência mecânica à flexão e retração linear. Essas propriedades de interesse cerâmico são referenciais para a performance do produto que se pretendeu gerar, principalmente quando se compara os resultados obtidos para corpos de prova de argila pura com aqueles obtidos para corpos de prova que receberam a adição de resíduos.

Para absorção de água e densidade aparente foi utilizado o método de ensaio NBR 6220(ABNT, 1997). Sendo dessa forma o corpo de prova após a queima deixada pra resfriar dentro do forno e pesados logo em seguida (Ms). Em seguida foram colocados em um recipiente, ao qual foi adicionado água para ebulição durante 2 horas. Durante a fervura os corpos de prova foram mantidos sempre cobertos pela água e afastados do fundo do recipiente. Após este tempo, o aquecimento foi interrompido e as amostras deixadas resfriar nesse meio até temperatura ambiente. A massa do corpo de prova imerso (Mi) foi determinada suspendendo-se o corpo de prova com um fio preso à balança. Em seguida, os corpos de prova foram retirados do recipiente, eliminando o excesso de água com um pano úmido. Eles foram então pesados (Msat) para determinação da massa do corpo de prova saturado. Foi calculada a absorção de água e densidade aparente pelas seguintes fórmulas:

$$
\begin{aligned}
& \mathrm{AA}(\%)=\frac{\text { Msat }-M s}{M s} \times 100 \\
& \mathrm{DA}\left(\mathrm{g} / \mathrm{cm}^{3}\right)=\frac{M \mathrm{Ms}}{\text { Msat }-\mathrm{Mi}}
\end{aligned}
$$

Onde:
$\mathrm{AA}=$ Absorção de Água (\%);
$\mathrm{DA}=$ Densidade Aparente $\left(\mathrm{g} / \mathrm{cm}^{3}\right)$; 
Ms = massa do corpo de prova após a queima $(\mathrm{g})$;

$\mathrm{Mi}=$ massa do corpo de prova imerso em água $(\mathrm{g})$;

Msat $=$ massa do corpo de prova saturado em água $(\mathrm{g})$.

Perda ao fogo que é importante na determinação da massa final do produto, com a massa dos corpos de prova secos em estufa a $110^{\circ} \mathrm{C}$ (Ms) e após a queima nas temperaturas determinadas anteriormente $(\mathrm{Mt})$, calculou-se a perda ao fogo (PF) pela equação:

$$
\mathrm{PF}(\%)=-\mathrm{Ms} \frac{(\mathrm{g})-\mathrm{Mt}(\mathrm{g})}{\mathrm{Ms}(\mathrm{g})} \times 100 .
$$

Onde:

$\mathrm{PF}=\mathrm{Perda}$ ao fogo $(\%)$;

$\mathrm{Mt}=$ peso corpos secos após queima $\left(850^{\circ} \mathrm{C}\right)$;

Ms = peso corpos secos em estufa $\left(110^{\circ} \mathrm{C}\right)$.

Retração linear com as medidas do comprimento da amostra após a extrusão (Lu) e do comprimento da amostra após a secagem a $110^{\circ} \mathrm{C}$ (Ls) calculou-se o valor da retração linear de secagem:

$$
R L(\%)=\frac{L u(c m)-L s(\mathrm{~cm})}{\operatorname{Lu}(\mathrm{cm})} \times 100 \% .
$$

Onde:

$R L=$ Retração Linear (\%);

Lu = comprimento após a extrusão;

Ms $=$ comprimento após secagem em estufa $\left(110^{\circ} \mathrm{C}\right)$.

Tensão de ruptura a flexão é uma maneira de verificar a resistência mecânica das peças quanto ao manuseio e suporte ao empilhamento da carga no enfornamento e 
transporte final. $O$ equipamento utilizado para esse ensaio foi a máquina de ensaios à flexão KRATOS, DEK 500/1000. A distância entre os apoios foi de $50 \mathrm{~mm}$ e o aumento de carga, conforme Método de ensaio e Procedimento, foi de $3 \mathrm{kgf} / \mathrm{s}$. A equação que determina o valor da tensão de ruptura é:

$$
\mathrm{TRF}=\frac{1,5 \cdot P \cdot \mathrm{L}}{\mathrm{a}^{2} \cdot \mathrm{b}}
$$

Onde:

$\mathrm{TRF}=$ tensão de resistência à flexão (MPa);

$\mathrm{P}=$ carga máxima atingida no momento da ruptura $(\mathrm{N})$;

$\mathrm{L}=$ distância entre os apoios $(\mathrm{mm})$;

$\mathrm{a}=$ espessura do corpo de prova $(\mathrm{mm})$;

$\mathrm{b}=$ largura do corpo de prova $(\mathrm{mm})$.

\section{RESULTADOS E DISCUSSÃO}

Foram analisados os corpos de prova queimados a $850^{\circ} \mathrm{C}$ e selecionadas cinco tipos de misturas: A (argila pura), B (argila $+5 \%$ de dregs), C (argila $+10 \%$ dregs), D (argila $+5 \%$ lama de cal) e $E$ (argila $+10 \%$ lama de cal). Segue abaixo a Figura $1 \mathrm{com}$ as amostras dos corpos de prova:

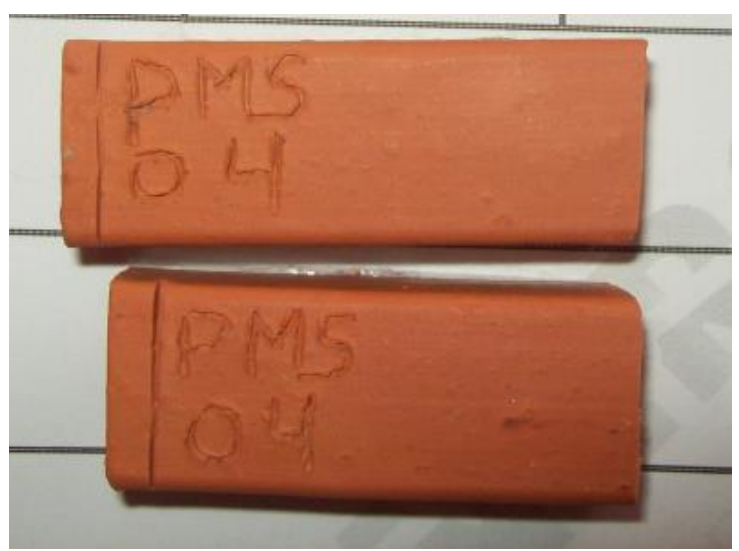

Figura1: Amostra dos corpos de prova queimados a 850 e $950^{\circ} \mathrm{C}$. 
Segundo normas da ABNT perda ao fogo dever ter um percentual inferior a $10 \%$, retração linear inferior a $6 \%$, absorção de água com percentual inferior a $20 \%$, tensão de ruptura superior a $20 \mathrm{Kgf} / \mathrm{cm}^{2}$ e densidade aparente superior a $1,7 \mathrm{~g} / \mathrm{cm}^{3}$. Os resultados comparativos das misturas sintetizadas a $850^{\circ} \mathrm{C}$ estão dispostos graficamente na Figura2.
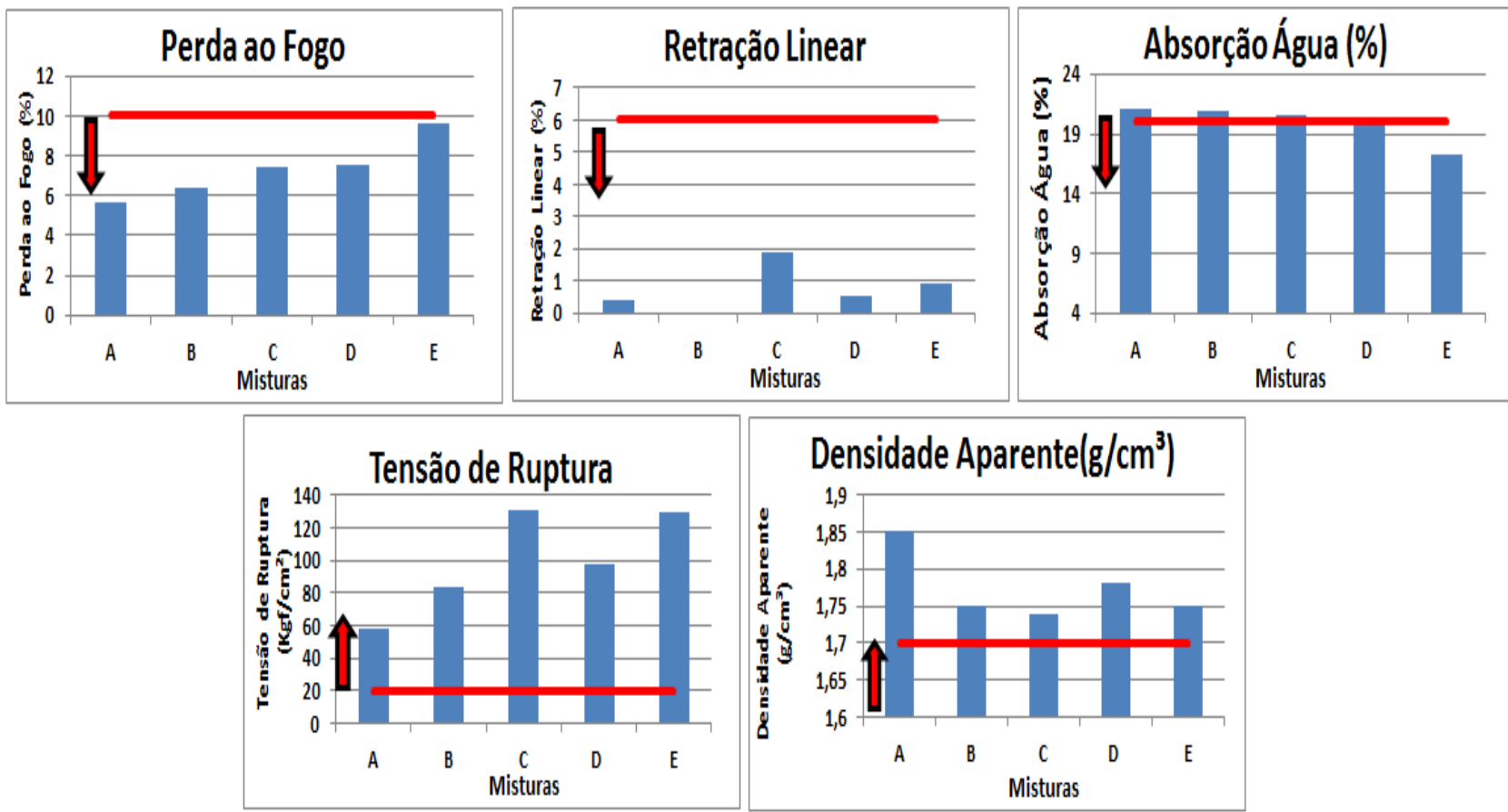

Figura2: Avaliação comparativa das misturas queimadas a $850 \stackrel{\circ}{C}$

De acordo com os resultados percebe-se que as misturas atendem aos valores de referência para a perda ao fogo $(P F \leq 10 \%)$ apenas a mistura $E$ fico próximo do limite especificado, à retração linear ( $R L \leq 6 \%)$ e tensão de ruptura à flexão (TRF $\geq 20 \mathrm{kgf} / \mathrm{cm}^{2}$ ) todas atenderam aos limites. No ensaio de Absorção de Água ( $A A \leq 20 \%$ ) a mistura $A$ ficou acima do desejado e Densidade Aparente $\left(D A \geq 1,7 \mathrm{~g} / \mathrm{cm}^{3}\right)$ todas as amostras atenderam as especificações.

\section{CONCLUSÃO}


A partir dos resultados obtidos em bancada, foram comprovadas as reais melhorias dos testes físicos, a formação de fases cristalinas responsáveis pela maior resistência mecânica à flexão do material cerâmico podendo ser utilizado parte do resíduo substituindo a argila nas indústrias de cerâmica minimizando a quantidade de resíduo descartado para aterro.

As análises dos resultados obtidos neste estudo permitem concluir que é possível a incorporação de resíduos do tipo dregs e lama de cal proveniente da fabricação de celulose, em argilas comuns utilizadas em indústria cerâmicas para a fabricação de produtos de cerâmica vermelha ou estrutural, tais como tijolos, blocos e telhas cerâmicas.

A cor pós-queima dos corpos de prova com esse percentual de resíduo praticamente não se alterou. Assim, por conterem elevados teores de elementos fundentes (particularmente cálcio) e teores pequenos de outros metais (inclusive ferro), os resíduos estudados apresentam potencial para incorporação a outros tipos de massas cerâmicas, podendo inclusive resultar em melhorias na qualidade dos produtos e principalmente numa diminuição na temperatura de queima (economia de energia na produção).

A produção de materiais cerâmicos para a construção civil (especialmente tijolos) a custos menores, pode estimular a substituição da madeira empregada nas habitações locais, predominantes hoje na região. Tal substituição poderia auxiliar na desejada diminuição do desmatamento na região. $O$ ensaio de solubilização com as amostras queimadas contendo resíduos mostrou que a introdução do dregs e da lama de cal, classificados pela atual legislação como "não inertes", à massa cerâmica, resultou em produto de estabilidade química atraente, inertizando quimicamente os resíduos. Esse fato é importante porque no caso do descarte de peças cerâmicas contendo os resíduos, na própria fabricação ou pós-consumo, os cacos e fragmentos gerados constituirão novos resíduos, mas desta vez de baixa agressividade ao meio ambiente.

\section{REFERÊNCIAS}


ASSOCIAÇÃO BRASILEIRA DAS CERAMICAS. Informações Técnicas dos Processos de Fabricação de Tijolos. Disponível em: <www.abceram.org.br>. Acesso em: 03 de julho de 2013.

ABNT - ASSOCIAÇÃO BRASILEIRA DE NORMAS TÉCNICAS. NBR 6459 - Solo Determinação do Limite de Liquidez. Rio de Janeiro. Associação Brasileira de Normas Técnicas, 1984a. 6 p.

NBR 6220 - Materiais refratários densos conformados - Determinação da densidade de massa aparente, porosidade aparente, absorção e densidade aparente da parte sólida Rio de Janeiro: ABNT, 1997, 2 p.

ANICER - Associação Nacional da Industria Cerâmica. Apresenta dados do setor em: <http://www.anicer.com.br>. Acesso em 10 de agosto de 2013.

ALVES, W. A.; BALDO, J. B. - O potencial da utilização de um resíduo argiloso na fabricação de revestimento cerâmico - Parte II. Cerâmica Industrial, São Paulo, v.3, n.1-2, p.34-36, 1998.

Disponível

em: <http://www.ceramicaindustrial.org.br/pdf/v03n12/v3n12_5.pdf>. Acesso em 28 de junho de 2013.

CENIBRA - CELULOSE NIPO-BRASILEIRA S/A. Relatórios técnicos da ETA CENIBRA no ano de 2006 e 2007. Belo Oriente. 2006.

CONAMA - Conselho Nacional do Meio Ambiente. Resolução n 264 de 1999. Disponível em: <http://www.mma.gov.br/port/conama/legiabre.cfm?codlegi=262>. Acesso em 25 de junho de 2013.

MENEZES, R. R.; NEVES, G. A.; FERREIRA, H. C. O estado da arte sobre o uso de resíduos como matérias-primas cerâmicas alternativas. Revista Brasileira de Engenharia Agrícola e Ambiental. v. 6, n. 2, p. 303-313, 2002. Disponível em: $<$ http://www.scielo.br/scielo.php?script=sci_arttext\&pid=S1415-43662002000200020\& Ing=pt\&nrm=iso\&tlng=pt >. Acesso em 28 de junho de 2013. 